\title{
Effect of Low-Level Laser Therapy on Peri-Implant Crestal Bone Loss and Pain Reduction during Initial Healing Period
}

\author{
Gayathri Danyasi ${ }^{1}$, Mulpuri Venkata Ramoji Rao ${ }^{2}$, Sathish Manthena ${ }^{3}$, Penubolu Lakshmi Preethi ${ }^{4}$, \\ Suneetha Koneru ${ }^{5}$, Pallavi Samatha Yalamanchili ${ }^{6}$, Venkata Naga Sri Harsha Anumolu ${ }^{7}$, Hemanth Ravella ${ }^{8}$ \\ 1, 2, 3, 4, 5, 6, 7, 8 Department of Periodontics and Implantology, Drs Sudha \& Nageswara Rao, Siddhartha \\ Institute of Dental Sciences, Chinaoutpalli, Gannavaram Mandal, Andhra Pradesh, India.
}

\section{ABSTRACT}

\section{BACKGROUND}

In recent days a high success rate has been documented for dental implants as a treatment option for missing teeth replacement. Low level laser therapy (LLLT) is a novel therapeutic modality reported to enhance bone healing. Few studies reported that LLLT enhances proliferation and differentiation of osteoblasts and also reduces postoperative pain. The purpose of this study was to assess if post-operative lowlevel laser irradiation of the implant site has any influence on crestal bone loss and pain reduction around dental implants.

\section{METHODS}

In this split mouth randomised study, 9 subjects with bilateral edentulous sites in the mandibular posterior region willing for replacement were taken into consideration. A total of 30 implants were placed on either side of the mandible followed by Low Level Laser irradiation on the test side immediately after implant placement, on $4^{\text {th }}$ and $7^{\text {th }}$ day. Crestal bone level assessment was done radiographically at 3 months and post-operative pain was assessed using visual analogue scale (VAS) scoring by patients from baseline to 6 days. Statistical analysis was done using unpaired t test for inter group crestal bone loss and Mann-Whitney $U$ test for intergroup pain reduction scores.

\section{RESULTS}

The mean crestal bone loss of control group was 1.40 with a standard deviation of 0.39 and for test group it was 0.76 with a standard deviation of 0.26 . A significant difference was observed between control and test groups with respect to crestal bone loss scores at 3 months. On comparing VAS pain scores between the two groups from day 1 to 6, significant difference between the groups was observed on day 2, 3 and 4 with P-values $0.042,0.0011,0.0036$ respectively.

\section{CONCLUSIONS}

Low level irradiation around the dental implants showed a significant reduction in crestal bone loss and post-operative pain.

\section{KEY WORDS}

Dental Implant, Low Level Laser Therapy, Crestal Bone Loss, Post-Operative Pain
Corresponding Author: Dr. Sathish Manthena, Drs Sudha \& Nageswara Rao Siddhartha Institute of Dental Sciences, Chinaoutpalli, Gannavaram Mandal -521 286, Andhra Pradesh, India. E-mail: sathishmanthena@gmail.com

\section{DOI: $10.14260 /$ jemds/2021/258}

How to Cite This Article:

Danyasi G, Rao MVR, Manthena $S$, et al. Effect of low-level laser therapy on peri implant crestal bone loss and pain reduction during initial healing period. J Evolution Med Dent Sci 2021;10(17):12081212, DOI: $10.14260 /$ jemds/2021/258

Submission 19-12-2020,

Peer Review 24-02-2021,

Acceptance 01-03-2021,

Published 26-04-2021.

Copyright (C) 2021 Gayathri Danyasi et al. This is an open access article distributed under Creative Commons Attribution License [Attribution 4.0 International (CC $B Y 4.0)]$ 


\section{BACKGROUND}

These days dental implants have become an optimal choice for rehabilitation of completely or partially edentulous patients. Branemark in the year 1969 defined Osseointegration as "a direct structural and functional connection between ordered living bone and the surface of the load bearing implant". 1

Preservation of bone support determines the long-term success of dental implants. LASER is an acronym for "Light Amplification by Stimulated Emission of Radiation". In dentistry LLLT is effectively used to accelerate healing or improve recovery in cases of aphthous ulcer, mucositis, herpetic lesions, nerve injuries ${ }^{2}$ and in the treatment of TMJ disorders. ${ }^{3}$

Unlike the normal lasers that are commonly used to produce thermally destructive and photocoagulation effects, low level lasers are used at low power density so that the target tissue temperature does not rise beyond the normal $\left(37^{\circ} \mathrm{C}\right)$ and produce photo stimulation effect within the tissue. In another study by Abbas, it was found that the low level laser application had stimulated bone formation and bone maturation around dental implants. ${ }^{4}$

In successfully osseointegrated implants, initial breakdown in the implant tissue interface starts at the crestal region. ${ }^{5}$ therefore evaluating the marginal bone level becomes an important criterion for determining the success of implants. The marginal bone loss is divided into two phases, the early bone loss and the late bone loss. The latter occurs as an infectious process after the prosthetic placement whereas the former occurs during the early phase of implant installation. In two stage dental implants there are various factors that contribute for early crestal bone loss- they are over exposure of the surgical site, heat generated during osteotomy, excessive pressure at the crestal region, implant malposition. 6,7

Very few clinical studies were conducted measuring the effect of low-level laser irradiation on initial bone loss around dental implants during healing. Therefore, this study was designed to assess if post-operative low-level laser irradiation of the implant site has any influence on crestal bone loss around dental implants and postoperative pain reduction during early healing period.

\section{METHODS}

This split mouth randomized study was conducted in The Department of Periodontics \& Implantology by Dr Sudha \& Nageswara Rao at Siddhartha institute of dental sciences from June 2018 to September 2019. A total of 9 periodontally stable subjects with 30 bilateral edentulous sites in the mandibular posterior region (premolars and molars) willing for replacement were taken into consideration. Sample size was calculated using inference for means tool from the site www.stat.ub.ca. An earlier study that assessed marginal bone loss was used to calculate. ${ }^{7}$ The edentulous sites should have adequate bone height $(\geq 10 \mathrm{~mm})$ and bone width $(\geq 5.5 \mathrm{~mm})$ and bone crest healing period of minimum 4 months prior to implant placement. Patients with systemic diseases contraindicating any type of surgery, under bisphosphonate therapy, chronic smokers, any evidence of pathology or active diseases of the implant bed, subjects who underwent radiation therapy were excluded from the study. Treatment plan was explained to all the patients and written informed consent was obtained. The study protocol was approved by the institutional ethical committee.

After implant placement the side to be irradiated (LLLT) was randomly assigned by the flip coin method with the other side remaining as control (Figure 1).

Patients were asked not to brush on the operated site for a week and other post-surgical instructions were given and recalled on 4th day for LLLT and on 7th day for LLLT and suture removal. Statistical analysis was done using SPSS software.

\section{Statistical Analysis}

Inter group comparison of bone loss between control group and test group at 3 months was done by unpaired t test. Comparison of implant diameter, length and comparison of pain scores at different time intervals between the groups was done by Mann-Whitney U test.

\section{RESULTS}

Among these 9 subjects, 3 were male (33.3\%) and 6 subjects were female ( $66.7 \%$ ) aged between $25-65$ years. Among the 9 subjects 1 subject received 6 implants, 4 subjects received 4 implants and 4 subjects received 2 implants each.

None of the implants had failed by the end of the study. Healing of all the implants was uneventful. No remarkable complications were noticed during the course of the study. There was no significant difference on comparing the mean diameter and length of implants between test and control groups (Table $1 \& 2$ ).

A significant difference was observed between control and test groups with respect to crestal bone loss scores at 3 months. The results of our study suggest that low level laser irradiated implant sites showed lesser crestal bone loss than the control sites which was statistically significant (P-value 0.0177 (Table 3).

\begin{tabular}{|ccc|}
\hline $\begin{array}{c}\text { Implant Diameter } \times \\
\text { Length in } \mathbf{~ m m}\end{array}$ & $\begin{array}{c}\text { No. of Implants in } \\
\text { Control Group }\end{array}$ & $\begin{array}{c}\text { No. of Implants in } \\
\text { Test Group }\end{array}$ \\
\hline $3.75 \times 11.5$ & 3 & 4 \\
$3.75 \times 13$ & 3 & 1 \\
$4.2 \times 10$ & 3 & 1 \\
$4.2 \times 11.5$ & 5 & 6 \\
$4.65 \times 10$ & 1 & 2 \\
$4.65 \times 11.5$ & 0 & 1 \\
\hline Table 1. Implant Size Distribution between Control and Test Groups \\
\hline
\end{tabular}

\begin{tabular}{|ccccccccc|}
\hline Groups & N & Mean & SD & $\begin{array}{c}\text { Mean } \\
\text { Rank }\end{array}$ & $\begin{array}{c}\text { U- } \\
\text { Value }\end{array}$ Value & $\begin{array}{c}\text { P- } \\
\text { Value }\end{array}$ \\
Diameter & Control & 15 & 4.05 & 0.27 & 14.43 & 96.500 & -0.731 & 0.512 \\
& Test & 15 & 4.14 & 0.33 & 16.57 & & & \\
Length & Control & 15 & 11.4 & 1.05 & 15.83 & $107.500-0.242$ & 0.838 \\
& Test & 15 & 11.3 & 0.77 & 15.17 & & \\
\hline Table 2. Comparison of Implant Diameter and Length between \\
Control Group and Test Group by Mann-Whitney U test \\
\hline P<0.05 (statistically significant)
\end{tabular}

On comparing VAS pain scores between two groups from day 1 - 6 significant difference between the groups were 
observed on day 2,3 and 4 with P-values $0.042,0.0011,0.0036$ respectively. Results of our study suggest that subjects experienced significant reduction in pain at implant sites that received low level laser therapy than the control sites. (Table 4).

\begin{tabular}{|c|c|c|c|c|c|c|}
\hline Time & Groups & Mean & SD & SE & $\begin{array}{c}\text { t- } \\
\text { Value }\end{array}$ & $\begin{array}{c}\text { P- } \\
\text { Value }\end{array}$ \\
\hline \multirow{2}{*}{3 months } & Control group & 1.40 & 0.39 & 0.10 & \multirow{2}{*}{5.210} & \multirow{2}{*}{$0.0177^{*}$} \\
\hline & Test group & 0.76 & 0.26 & 0.66 & & \\
\hline \multicolumn{7}{|c|}{$\begin{array}{l}\text { Table 3. Intergroup Comparison of Crestal Bone Loss between } \\
\text { Control Group and Test Groups at } 3 \text { Months by Unpaired T Test }\end{array}$} \\
\hline \multicolumn{7}{|c|}{$\mathrm{P}<0.05$ (statistically significant) } \\
\hline
\end{tabular}

\begin{tabular}{|c|c|c|c|c|c|c|c|c|c|}
\hline \multirow{2}{*}{$\begin{array}{l}\text { Time } \\
\text { Points }\end{array}$} & \multicolumn{3}{|c|}{ Control Group } & \multicolumn{3}{|c|}{ Test Group } & \multirow{2}{*}{\multicolumn{2}{|c|}{$\begin{array}{c}\text { U- } \\
\text { Value } \\
\text { Value }\end{array}$}} & \multirow{2}{*}{$\begin{array}{c}\text { P- } \\
\text { Value }\end{array}$} \\
\hline & Mean & SD & $\begin{array}{r}\text { Mean } \\
\text { Rank }\end{array}$ & Mean & SD & $\begin{array}{c}\text { Mean } \\
\text { Rank }\end{array}$ & & & \\
\hline Day 1 & 3.78 & 0.44 & 11.00 & 3.44 & 0.53 & 8.00 & 27.00 & -1.1921 & 0.2332 \\
\hline Day 2 & 3.44 & 0.53 & 12.06 & 2.78 & 0.44 & 6.94 & 17.50 & -2.0309 & $0.0423^{*}$ \\
\hline Day 3 & 2.89 & 0.33 & 13.61 & 1.78 & 0.44 & 5.39 & 3.50 & -3.2672 & $0.0011 *$ \\
\hline Day 4 & 2.44 & 0.53 & 13.17 & 1.33 & 0.50 & 5.83 & 7.50 & -2.9140 & $0.0036^{*}$ \\
\hline Day 5 & 1.44 & 0.53 & 11.50 & 1.00 & 0.00 & 7.50 & 22.50 & -1.5894 & 0.1120 \\
\hline Day 6 & 1.00 & 0.00 & 9.50 & 1.00 & 0.00 & 9.50 & 40.50 & 0.0000 & 1.0000 \\
\hline \multicolumn{10}{|c|}{$\begin{array}{c}\text { Table 4. Comparison of Control and Test Groups with } \\
\text { Mean VAS Scores at Day 1, Day 2, Day 3, Day 4, Day } 5 \\
\text { and Day } 6 \text { Time Points by Mann-Whitney U Test }\end{array}$} \\
\hline & statistica & 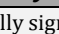 & cant & & & & & & \\
\hline
\end{tabular}

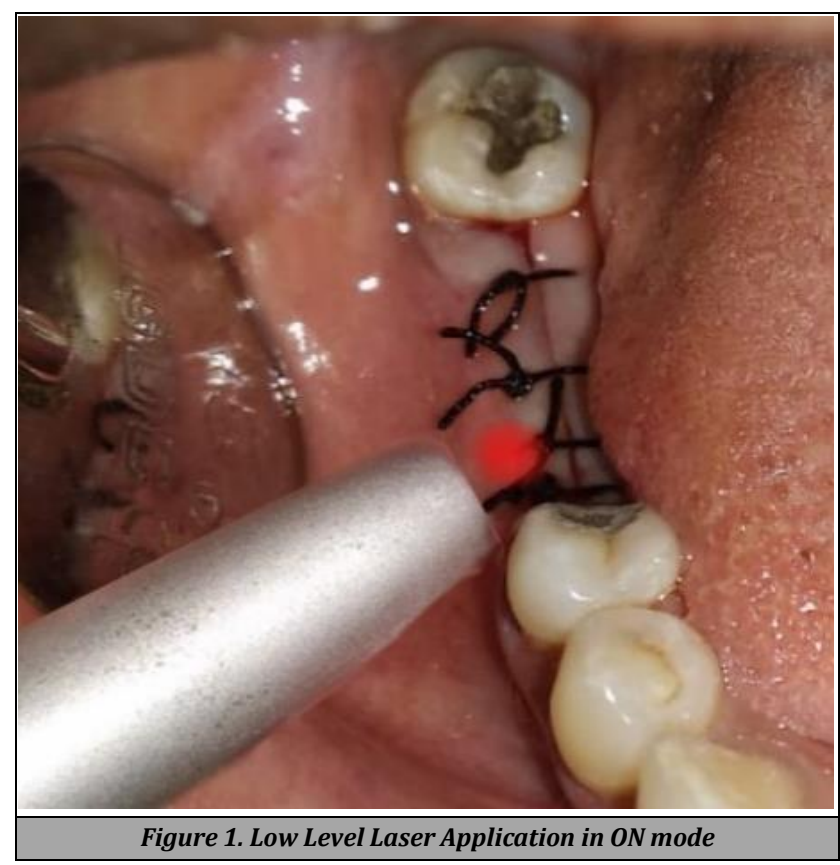

\section{DISCUSSION}

Preservation of bone support around the dental implant determines the long-term clinical success of dental implants. As per Albrektsson's criteria for successful implants the marginal bone remodelling should be less than $2.0 \mathrm{~mm}$ in the first year after implant placement and less than $0.2 \mathrm{~mm}$ each year thereafter. ${ }^{8}$ Early crestal bone loss depends mainly on the surgical trauma during the placement of implant which includes excessive reflection of the periosteal flaps, prolonged exposure of the osteotomy site to the external environment and due to excessive pressure, that is applied on the bone during the placement of implant. ${ }^{9}$ To minimize these factors it was made sure that all the implants in the study were placed in the least traumatic way possible.

Apart from surgical considerations many modifications were done in the structure of implants which includes incorporation of micro threads or rings at the implant shoulder and by exposing the implant to different surface treatments such as sand blasting, acid etching and different surface coatings such as hydroxyapatite, growth factors such as PRP, PRF etc. which increases the bone-implant contact and helps to minimize the early crestal bone loss around implants. ${ }^{10}$ The implants used in this study were Alpha Bio ICE implants which consisted of micro rings at the coronal part which itself helps to increase the bone-implant contact at the crestal region. These implants have double threaded design with $2 \mathrm{~mm}$ step and the apical part of the implant is narrow with sharp and deep apical threads and has a flat apical border. These implants were sand blasted and double acid etched which increases the surface area on the implant enabling a more intense absorption of blood and plasma proteins directly into the implant micropores immediately after the implant placement which ultimately enhances the bone-implant contact. This micro structure and roughness created by the sand blasting and acid etching process greatly influences the dynamic wet ability of implant surfaces during the initial contact with the host.

The term "LASER - Light Amplification by Stimulated Emission of Radiation" was coined by Gordon Gould in 1956. The first laser was developed by Theodore Maiman ${ }^{11}$ in the year 1960 which has ruby crystal as an active medium. From then onwards many developments took place and different types of lasers have been introduced. The lasers which do not increase the body temperature are known as low level lasers or cold lasers which were discovered by Endre Mester. In 1968, Mester ${ }^{12}$ through his experiments with ruby laser on rats with implanted tumours observed that though the laser was not able to destroy the tumour completely it resulted in fastening the healing of surgical incisions. With these observations Mester focussed his research on the application of LLLT for the accelerating of tissue healing process.

LLLT has historically been classified as non-thermal therapeutic modality because its therapeutic effects were not associated with a heating response, the effects were due to photochemical response. Chromophores in the cell trigger a photochemical reaction to the photons released by LLLT thus producing a desirable physiological effect. These LLLT work at a power of $<500 \mathrm{~mW}$ and is classified under class IIIb lasers. ${ }^{13}$ BelangerAY (2002) ${ }^{14}$ reported that the depth of penetration of shorter wavelength used in LLLT (620 mm - $695 \mathrm{~mm}$ ) was up to $1 \mathrm{~cm}^{2}$ and the depth of penetration of longer wavelengths $(760 \mathrm{~nm}-1000 \mathrm{~nm})$ was $5 \mathrm{~cm}^{2}$. LLLT is used in medicine in the field of orthopaedics, ophthalmology to relieve pain and also accelerate healing in cases of trauma. Orhan Dortbudak $(2000)^{15}$ conducted a study to evaluate the effect of LLLT on osteoblasts and found that LLLT enhances bone maturation and formation and therefore can be used to improve osseointegration around dental implants. Many studies were conducted to evaluate the effects of LLLT on osseointegration of dental implants and attained positive results. Very few studies were conducted on marginal bone loss and reduction in pain level after implant placement; therefore, this study was 
designed to evaluate the effect of LLLT on marginal bone loss and reduction in pain scores around dental implants.

After the placement of prosthesis post loading factors also play a role in crestal bone changes; therefore, in order to avoid the effect of these factors this study aimed to evaluate the effects of laser on peri-implant crestal bone in the early phases of bone healing ( 3 months).

The rationale behind the use of LLLT is its action at cellular level to enhance tissue healing. Light absorption with in the mitochondria of the cells is the keystone for the effects of LLLT. mitochondria within the cells are responsible for the generation of cellular energy using oxygen and pyruvate. In case of cell injury or stressed cells there will be increased production of nitric oxide by the mitochondria that competes with oxygen from binding to Cytochrome c Oxidase thus reducing energy generation by mitochondria, this results in increased oxidative stress leading to inflammation.

When stressed cells were subjected to LLLT it was observed that there was increase in ATP synthesis, release of nitric oxide by $\mathrm{CcO}$ and decrease in oxidative stress. These effects directly or indirectly affect the components in the cell membrane, cytosol, and nuclear functions that control cellular responses such as proliferation, migration, necrosis and inflammation. LLLT can also affect the tissues that have not absorbed photons, indirectly via the bioactive molecules released from the stimulated cells, these indirect effects are termed as "bystander" effects. ${ }^{16}$ The molecular aspects in the mechanism of bone fracture healing were explained by Rozalia Dimitriou $^{17}$ in 2005. According to this on the first day of healing there will be hematoma formation and LLLT is known to increase the angiogenesis. By the 4th day mesenchymal stem cell proliferation begins with proliferation and differentiation of pre-osteoblasts and osteoblasts. As LLLT increases the osteoblast proliferation and viability of osteocytes there will be faster differentiation of preosteoblasts to osteoblasts. By 7 th day there will be peak proliferation of osteoblasts and as LLLT has an additive effect there will be more and more proliferation of osteoblasts. Based on these, LLLT was irradiated at baseline i.e., immediately after the placement of implants, on 4 th and 7 th day, in this study. These irradiations were correlated with the irradiations performed in the study conducted by Khalid E ElKholey $^{7}$ in 2012.

In this study a visual analogue score was used to evaluate the pain scores and to standardise the pain values all the patients were asked to mark the pain score on the chart given to them every evening between $4-5 \mathrm{pm}$. Both the sides showed gradual reduction of pain from day 1 to day 6 but the side that received LLLT showed faster reduction when compared to the non-irradiated side. Similar results were obtained in the study conducted by Mohadeseh Heideri (2018) ${ }^{18}$ in which the effect of LLLT on pain after periodontal flap surgery was evaluated. Chow et al. (2011) ${ }^{19}$ in his systematic review proposed a mechanism in which laser light decreases the amplitude and conduction velocity of action potential of the nociceptors, thus exerting an inhibitory effect on $\mathrm{A}$ and $\mathrm{C}$ pain fibres. They also suggested that in dorsal root ganglion LLLT inhibits the anterograde transport of ATP, thus inhibiting neurogenic inflammation.

\section{CONCLUSIONS}

Within the limitations of the study, low level irradiation around the dental implants showed a significant reduction in crestal bone loss and post-operative pain. Most of the studies were done to evaluate the effect of LLLT on stability of dental implants and very limited studies were done on the crestal bone loss. In this study, implants with micro threads at the coronal part were used which itself helps to reduce the bone loss. Further long-term studies should be conducted to assess if LLLT can preserve the bone at the crestal region of the implants without any micro threads and also after the placement of prosthesis.

\section{Limitations of the Study}

This study could not measure the bone density around the implant sites and the angulation and distance of the laser hand piece from the osteotomy site and the depth of penetration of the laser beam were not standardised.

Data sharing statement provided by the authors is available with the full text of this article at jemds.com.

Financial or other competing interests: None.

Disclosure forms provided by the authors are available with the full text of this article at jemds.com.

\section{REFERENCES}

[1] Branemark PI, Breine U, Adell R, et al. Intra-osseous anchorage of dental prostheses. I. Experimental studies. Scand J Plast Reconstr Surg 1969;3(2):81-100.

[2] Suresh S, Merugu S, Mithradas N. Low-level laser therapy: a biostimulation therapy in periodontics. SRM J Res Dent Sci 2015;6(1):53-6.

[3] Mazzetto MO, Hotta TH, Pizzo RC. Measurements of jaw movements and TMJ pain intensity in patients treated with GaAlAs laser. Braz Dent J 2010;21(4):356-60.

[4] Issmaeel SA, Abbas AH. The effect of low-level laser on osseointegration of dental implants. Journal of Baghdad College of Dentistry 2011;23(3):112-6.

[5] Prasad DK, Shetty M, Bansal N, et al. Crestal bone preservation: a review of different approaches for successful implant therapy. Indian J Dent Res 2011;22(2):317-23.

[6] Oh TJ, Yoon J, Misch CE, et al. The causes of early implant bone loss: myth or science? J Periodontol 2002;73(3):322-33.

[7] El-Kholey KE, El-Shenaway H. Role of diode laser in preservation of the marginal bone around early loaded endosseous implant. Life Sci J 2012;9(3):940-3.

[8] Albrektsson T, Zarb G, Worthington P, et al. The longterm efficacy of currently used dental implants: a review and proposed criteria of success. Int J Oral Maxillofac Implants 1986;1(1):11-25.

[9] Oh TJ, Yoon J, Misch CE, et al. The causes of early implant bone loss: myth or science? J Periodontol 2002;73(3):322-33.

[10] Feighan JE, Goldberg VM, Davy D, et al. The influence of surface-blasting on the incorporation of titanium-alloy implants in a rabbit intramedullary model. J Bone Joint 
Surg 1995;77(9):1380-95.

[11] Maiman TH. Optical and microwave-optical experiments in ruby. Phys Rev Lett 1960;4(11):564-6.

[12] Mester E, Szende B, Gartner P. The effect of laser beams on the growth of hair in mice. Radiobiol Radiother (Berl) 1968;9(5):621-6.

[13] Hecht J. A short history of laser development. Appl Opt 2010;49(25):F99-122.

[14] Belanger AY. Evidence-based guide to therapeutic physical agents. $1^{\text {st }}$ edn. Phildelphia: Lippincott Williams \& Wilkins 2002.

[15] Dortbudak O, Haas R, Mailath-Pokorny G. Biostimulation of bone marrow cells with a diode soft laser. Clin Oral Implants Res 2000;11(6):540-5.

[16] Carroll JD, Milward MR, Cooper PR, et al. Developments in low level light therapy (LLLT) for dentistry. Dent Mater 2014;30(5):465-75.

[17] Dimitriou R, Tsiridis E, Giannoudis PV. Current concepts of molecular aspects of bone healing. Int J Care Injured 2005;36(12):1392-404.

[18] Heidari M, Fekrazad R, Sobouti F, et al. Evaluating the effect of photobiomodulation with a 940-nm diode laser on post-operative pain in periodontal flap surgery. Lasers Med Sci 2018;33(8):1639-45.

[19] Chow R, Armati P, Laakso EL, et al. Inhibitory effects of laser irradiation on peripheral mammalian nerves and relevance to analgesic effects: a systematic review. Photomed Laser Surg 2011;29(6):365-81. 